\title{
Perfil dos turistas do Parque Estadual da Serra do Brigadeiro (MG): subsídios para o turismo comunitário ${ }^{1}$
}

\section{Werter Valentim Moraes, Guido Assunção Ribeiro, Virgilio Furtado Dornelas, Renato Miranda Cardoso, Ivanete Freitas Araponga}

\begin{abstract}
RESUMO
O turismo de base comunitária vem se destacando no cenário turístico nacional, devido, principalmente, à disponibilização de valores agregados à economia local inserida com a atividade turística. Assim, o projeto boas práticas com o turismo comunitário no território da Serra do Brigadeiro desenvolvido pelo - Centro de Pesquisa e Promoção Cultural - CEPEC, financiado pelo Ministério do Turismo, visa maximizar valores agregados, demonstrando que a região, com sua organização social e ambiental, apresenta condições de assumir a cadeia produtiva do turismo através da agricultura familiar, aliando-se ao Parque Estadual da Serra do Brigadeiro - PESB com seus atrativos naturais. A área de abrangência desta pesquisa é o entorno do PESB, que limita com o município de Araponga, sede da administração da referida Unidade de Conservação (UC). A proposta é conhecer o usuário da Unidade de Conservação, com o intuito de identificar os atrativos turísticos visitados e sua infra-estrutura, valorizando a aptidão da região com sua agricultura familiar. Os dados iniciais indicam a pré-disposição dos turistas pelos produtos e serviços da agricultura familiar e a necessidade de uma melhor organização dos empreendedores locais e agricultores familiares para um intercâmbio, e uma identificação dos possíveis canais de comercialização.
\end{abstract}

PALAVRAS-CHAVE: Unidade de Conservação; Pesquisa de Mercado; Ecoturismo de Base Comunitária

\section{Parque Estadual da Serra do Brigadeiro (MG, Brazil)'s tourists' profile: subsidies for community-based tourism}

\begin{abstract}
Community-based tourism is increasing in the national tourism scenario, mainly for providing value-added services to the local economy and tourism activity. The project "Good Practices for Community Tourism in the Territory of Serra do Brigadeiro" developed by the Center of Research and Cultural Promotion - CEPEC - and funded by the Ministry of Tourism, aims to maximize these added values, showing that the region, together with its social and environmental organization, is a strong tourism product that should be incorporated to the Parque Estadual da Serra do Brigadeiro. The area covered by this research consists of the conservation unit and its surroundings, whose borders are shared with the city of Araponga. The main objectives of this study are to identily the visitor of the conservation unit and diagnose the tourist attractions and infrastructure, together with the development of guidelines for community-based tourism and value of the regional aptitude for family farming. Preliminary data indicate potential for community tourism in the region and interest of the target audience in reference to these tourism products.
\end{abstract}

KEYWORDS: Protect Area; Market Research; Community-based Ecotourism. 
Perfil dos turistas do Parque Estadual da Serra do Brigadeiro: subsídios para o turismo comunitário.

\section{Introdução}

As ações relatadas neste artigo foram desenhadas em reuniões, cursos e oficinas de turismo realizadas no âmbito do Território da Serra do Brigadeiro TSB, onde se insere a Unidade de Conservação do Parque Estadual da Serra do Brigadeiro, gerenciada pelo Instituto Estadual de Florestas - IEF, do estado de Minas Gerais. A proposta de se desenvolver o turismo de base comunitária iniciou-se a partir de 2006, dentro do Programa de Turismo para este Território, financiado pelo Ministério do Desenvolvimento Agrário - MDA, pois já se trabalha na região uma articulação com a REDE TRAF - Turismo Rural na Agricultura Familiar desde o ano de 2003.

O turismo no espaço rural é um dos eixos temáticos do Território, sendo discutido desde a data de sua criação em 2003. Assim, o CEPEC desenvolveu o Projeto "Casa da Cultura" em 2004, e "Inventário Cultural da Serra do Brigadeiro" em 2007, com recursos do MDA. A EMATER desenvolveu o projeto "Planos Municipais de Turismo no Território da Serra do Brigadeiro" em 2004, através do aporte financeiro do MDA, até 2007.

Com base nesse conjunto de projetos, o CEPEC e a Associação Amigos de Iracambi, que gerencia a Reserva Particular do Patrimônio Natural Iracambi e o Centro de Pesquisa Iracambi, membros do Conselho Gestor do Território apresentam o referido projeto de turismo de base comunitária, intitulado "Boas Práticas para o Turismo Comunitário". Neste, se pretende aplicar as estratégias da Rede de Turismo Rural da Agricultura Familiar - TRAF e a metodologia "Receitas para o Sucesso do Turismo de Base Comunitária - TBC" do Programa de Redução da Pobreza pela Exportação - PRPE, tendo como fonte a International Trade Centre UNCTAD/WTO 2004.

A área de abrangência do projeto envolverá os municípios de Araponga, Rosário de Limeira, Fervedouro, Miradouro, Divino, Sericita, Pedra Bonita, e Muriaé, estabelecendo as bases de trabalho localizadas estrategicamente na vertente oriental em Araponga e na vertente ocidental em Rosário de Limeira. As instituições envolvidas são: a Emater, o IEF, através da Unidade de Conservação do Parque Estadual da Serra do Brigadeiro, as Escolas Famílias Agrícolas, a Associação dos Municípios Integrantes do Circuito Turístico da Serra do Brigadeiro - ABRIGA, os Sindicatos de Trabalhadores Rurais e as Associações Comunitárias e os Grupos Organizados que já atuam em parceria com o CEPEC nas ações de cultura e turismo.

Nesta região, já existe certo fluxo de turistas nacionais e internacionais, atraídos pelo programa de voluntariado da Associação Amigos de Iracambi, que recebe uma média de 100 voluntários por ano (2007), totalizando a visita de 36 países que se interessam pelo desenvolvimento da atividade turística solidária e científica. 
Moraes, W.V.; Ribeiro, G.A.; Dornelas, V.F.; Cardoso, R.M.; Araponga, I.F.

\section{O Parque Estadual da Serra do Brigadeiro}

O Parque Estadual da Serra do Brigadeiro conta com uma área total de 14.984 hectares onde predomina a Mata Atlântica. Foi criado em 27 de junho de 1996, através do Decreto No 38.319, que no seu parágrafo único previa: O Parque Estadual de que se trata o artigo tem por finalidade proteger a fauna e a flora regionais, as nascentes de rios e córregos da região, além de criar condições ao desenvolvimento de pesquisas científicas e à ampliação do turismo ecológico na região.

O Parque Estadual da Serra do Brigadeiro abrange os municípios mineiros de Araponga, Fervedouro, Miradouro, Ervália, Sericita, Muriaé, Divino e Pedra Bonita, e tem vários Picos: o do Soares (1.985 metros de altitude), o Campestre (1.908 m), o do Grama $(1.899 \mathrm{~m})$ e o do Boné $(1.870 \mathrm{~m})$. São 13.210 hectares de matas nativas e uma paisagem dominada por montanhas, vales, chapadas e encostas e diversos cursos d'água que integram as bacias dos rios Paraíba do Sul e Doce (IEF, 2002).

O Plano de Manejo da Unidade de Conservação já foi elaborado estando em fase de execução, com programas específicos de turismo rural e ecoturismo, com gestão participativa através do Conselho Participativo de Gestão do Parque Estadual da Serra do Brigadeiro, o que possibilita uma grande aprendizagem de gestão do turismo de base comunitária.

\section{Comunidades da Serra do Brigadeiro}

Os municípios pertencentes a Serra do Brigadeiro, no entorno do Parque Estadual da Serra do Brigadeiro, são compostos por comunidades que detém sua cultura ainda bastante preservada e um ambiente de grande beleza cênica e relevância ambiental. Pode ser observada a utilização de alternativas centenárias na produção de alimentos e moradia, além da região manter seu calendário de eventos, com inúmeras festividades religiosas como festas juninas, cavalgadas, peregrinações, folia de reis e o famoso forró do interior.

Entretanto, as comunidades enfrentam problemas como o êxodo rural, ocasionado pela sedutora vida urbana e pelo desmatamento ocasionado pela diminuição da produtividade e a infertilidade do solo, que aumenta o consumo de insumos inorgânicos e demanda maiores áreas para plantio. Estes fatores agravam questões sociais como o aumento do índice de prostituição, consumo de entorpecentes, pobreza, doenças por poluição entre outros.

Em termos de produção agrícola, o café se destaca como o principal produto do Território, ocupando a maior parte da área plantada. Porém, o volume produzido não reflete o maior valor da produção, muito provavelmente em função da baixa produtividade e qualidade do café. Municípios onde os agricultores vêm buscando a produção de cafés de qualidade têm obtido um maior valor da produção por hectare (VP/ ha), como é o caso de Araponga, que, embora tendo uma das menores áreas plantadas com café do território, conta com um bom índice de VP/ha (MDA, 2003). Assim, o 
Perfil dos turistas do Parque Estadual da Serra do Brigadeiro: subsídios para o turismo comunitário.

café de Araponga é detentor, por três anos consecutivos, do prêmio de melhor café do Brasil, tornando-se um potencial produto turístico a ser explorado neste projeto.

A Serra do Brigadeiro encontra-se ameaçada, muito devido ao rápido avanço de modelos desenvolvimentistas que suprimem as culturas tradicionais. Sendo assim, deve-se incentivar a implantação de atividades mais sustentáveis que aproveitem dos potenciais locais para gerar uma melhor qualidade de vida no meio rural, resgatando, preservando e promovendo o ambiente natural.

Desta forma, o turismo de base comunitária surge como uma ferramenta para impulsionar a prazerosa vida no campo e proporcionar aos visitantes potenciais uma maior consciência e valorização destes ambientes, patrimônios, pessoas e suas características culturais.

\section{O Conceito de Território}

De acordo com a Secretaria de Desenvolvimento Territorial - SDT, uma questão a ser pensada é como se delimita o espaço em que as relações sociais, ambientais e culturais acontecem. No Brasil houve alguns estímulos para discussões relativas às caracterizações destas áreas geográficas atendidas por uma política pública federal, que se iniciou na década de 90, com o Programa Comunidade Solidária, onde o foco era o município. Já a SDT não trabalha em espaço politicamente definido porque seu foco é gente, o que condiz com decisões que favorecem só alguns, mas sim um grupo que tenha coisas em comum. As fronteiras jurídicas e políticas não respeitam estes princípios.

Segundo MDA (2003), a Secretaria de Desenvolvimento Territorial definiu território como sendo o espaço que afetivamente as pessoas se sentem vinculadas. O documento pondera que é difícil trabalhar com uma política pública cuja definição é tão sentimental, mas reconhece que quando se vai a um território é possível se perceber as referências e valores comuns das pessoas que ali vivem. Muitas coisas têm valor para as pessoas que vivem no local, mas não são reconhecidas pelo governo, como, por exemplo, festas, tradições, entre outras características culturais. Aspectos como esses definem a identidade de um território. O estímulo comum, despertado pelas pessoas que ali vivem, é a dinâmica capaz de impulsionar ações que condizem com o estímulo governamental. No entanto, na maior parte das vezes, um município não define esse tipo de sentimento, mas se até apenas à questão jurídica. O que torna ainda mais complexa a situação é que em um mesmo município pode haver mais de um território, dificultando a proposição de políticas públicas. Já em outros casos, mesmo comunidades distantes se sentem parte de um mesmo território.

Segundo o MDA (2003) a Secretaria de Desenvolvimento Territorial enumerou vários elementos para detectar territórios: o sentimento de pertencimento, o padrão histórico produtivo, a manifestação étnica, as práticas religiosas e festas comuns, entre outros. Mas, é o sentimento de pertencimento a um território o mais determinante 
que todos os demais, e portanto, deve ser o principal fator de políticas públicas para a transformação. $O$ documento afirma que devem ser dadas as condições para que 0 povo de um território efetive suas escolhas e assim se empodere.

Na realização do Plano de Desenvolvimento Territorial, foram trabalhadas as seguintes identidades territoriais:

- O Parque Estadual da Serra do Brigadeiro;

- O cultivo do café de montanha, ou café de altitude de qualidade;

- A agroecologia ;

- A cultura (festas, religião, hábitos, crenças);

- A predominância da agricultura familiar;

- O solo, o clima e relevo da região;

- Os trabalhos de artesanato;

- O potencial para o ecoturismo e o turismo rural;

- A estrutura fundiária;

- A criminalidade ocorrida por conflitos fundiários em uma determinada época, em especial nas comunidades do entorno do Parque que são mais isoladas;

- A falta de infra-estrutura;

- A religiosidade como aglutinadora;

- A herança cultural indígena dos povos Puris;

- A interação entre as comunidades do entorno do Parque;

- A luta unida das comunidades no processo de criação do Parque da Serra do Brigadeiro;

- A água de boa qualidade e medicinal.

Ressaltou-se que o limite do território não é político, pois as comunidades do entorno do Parque têm grande identidade entre si.

\section{O Eixo Temático do Turismo Rural}

Segundo o CTA-ZM (2005), no Plano de Desenvolvimento Territorial foram definidos vários eixos temáticos. Este documento traz os debates realizados e as definições tomadas em busca do desenvolvimento com sustentabilidade para a região. Para tal, foram definidos como eixos estratégicos de ação nas as comunidades do entorno do Parque Estadual da Serra do Brigadeiro: Preservação e Recuperação do Meio Ambiente, Turismo Rural, Agricultura Familiar Diversificada, Agroindústria Familiar e Artesanato e Cultura.

No eixo Turismo Rural, pretende-se explorar o potencial turístico do Parque Estadual da Serra do Brigadeiro e do Território de maneira a promover a qualidade de vida das comunidades sem, no entanto, descaracterizá-las e/ou desrespeitá-las. O 
Perfil dos turistas do Parque Estadual da Serra do Brigadeiro: subsídios para o turismo comunitário.

benefício deve ser para todos os municípios, permitindo e facilitando a circulação de recursos dentro do território com o intuito de gerar ocupações rentáveis aos moradores, e visando o desenvolvimento econômico, social e ambiental do mesmo.

São oito (08) as ações que estão sendo trabalhadas no Território:

- Ação1: Elaboração do Plano de Turismo Sustentável do Território, que compreende a realização de um inventário sobre potencialidades e necessidades para o desenvolvimento do turismo, a divulgação dos atrativos turísticos e o ordenamento do turismo.

- Ação2: Capacitação de moradores/as para o turismo, que é um processo amplo de formação considerando o que acontece em cada local e as experiências de cada participante. Serão, assim, realizados cursos e intercâmbios, além da capacitação de prefeitos e vereadores acerca do tema, que inclui a conscientização e capacitação da população e a melhoria da segurança.

- Ação 3: Proporcionar para a população informações para se relacionar com os turistas, como por exemplo, quem são, de onde vêem, qual o interesse dos mesmos na região, acesso a pontos turísticos.

- Ação 4: Busca de recursos para investir nas propriedades, com base nas fontes de apoio definidas pelo PRONAF e cooperativas de crédito, com os possíveis executores sendo os Sindicatos dos Trabalhadores Rurais e associações locais.

- Ação 5: Incentivar e promover a discussão do turismo adequado para cada município.

- O grupo gestor do Território da Serra do Brigadeiro colocou os impactos que o turismo pode causar nas comunidades se não houver preparação e adequação dos municípios e comunidades para trabalhar o turismo. Assim, o grupo levantou a necessidade de uma nova ação com moradores, organizações populares, poder público e setores estratégicos como educação e saúde, contando com o apoio do MDA, Ministério do Turismo e IEF. O grupo levantou como possíveis executores o CEPEC e outras organizações locais e as prefeituras.

- Ação 6: Construção de Centros de Informações Turísticas, que têm a finalidade de disseminar informações turísticas e comercialização de produtos do território em cada município.

- Ação7: Incentivar eventos culturais envolvendo as comunidades. O grupo vê a importância dessa ação, entendendo a cultura popular tradicional como mais equilibrada e harmoniosa com a natureza. Os possíveis executores são o CEPEC, as comunidades e as prefeituras. As fontes de apoio para a realização dessa ação podem ser as organizações locais e as Escolas Famílias Agrícolas. Estes eventos poderão ser uma opção de lazer para os moradores e atrativos para turistas.

- Ação 8: Melhoria da Infra-Estrutura de estradas e sinalização das mesmas, priorizando a atividade turística. 


\section{O Que se Pretende Realizar}

Uma definição do Turismo Baseado na Comunidade - TBC é apresentada pelo UNCTAD/WTO (2005, p.27) baseado no Encontro de Catmandu, no Nepal, que afirma o seguinte: "Uma interação visitante/anfitrião, cuja participação é significativa para ambos e gera benefícios econômicos e de preservação para as comunidades e o meio ambiente local".

Jain e Lama (2000) sugerem que o TBC pode tomar outras formas tais como a valorização dos saberes e fazeres transformados em produtos turísticos, tendo como princípio os bens naturais e culturais da região. Neste sentido o turismo de base comunitária resulta no ganho de receitas para as comunidades anfitriãs, manter sua cultura e preservar seus recursos.

Quadro 1 - Receitas para o Sucesso do Turismo de Base Comunitária - TBC no Programa de Redução da Pobreza pela Exportação - PRPE.

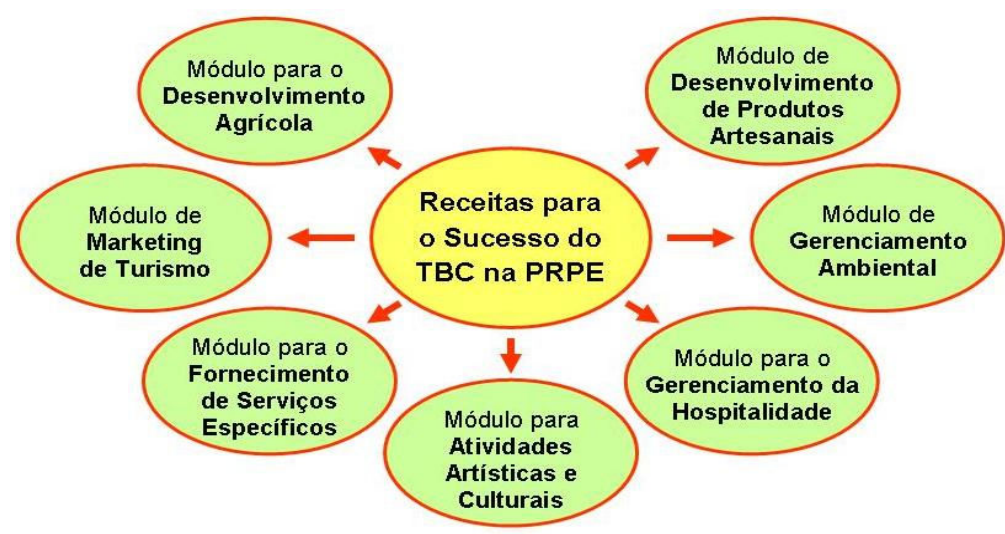

Fonte: International Trade Centre UNCTAD/WTO, 2004.

Os Sete Módulos de Formação do TBC, conforme UNCTAD/WTO (2005, p.37), são:

- Comercialização do Turismo - ensina responsáveis de acolhimento a selecionar operadores turísticos locais, postos de turismo, agências de viagens. O módulo põe em evidência, estratégias de comercialização, marketing mix e promoção.

- Desenvolvimento de Produtos Artesanais - visa à criação de associações de fabricantes de artesanato. O módulo trata do reforço das capacidades de produção e comercialização dos produtores artesanais.

- Desenvolvimento Agrícola - visa formar ou fortalecer associações de produtores agrícolas. O módulo põe em evidência o reforço das capacidades de produção e comercialização dos produtores agrícolas. 
Perfil dos turistas do Parque Estadual da Serra do Brigadeiro: subsídios para o turismo comunitário.

- Gestão de Acolhimento dos Turistas - visa capacitar associações para alojamento de turistas, restaurantes, estâncias, e proprietários de cafés. O objetivo é reforçar os serviços competitivos de todas as empresas envolvidas.

- Atividades Culturais e Artísticas - visa permitir às comunidades, explorarem o seu patrimônio cultural único e propor divertimento (danças, folclore, espetáculos etc..) de uma maneira profissional e rentável.

- Prestação de Serviços Específicos - reforça as competências e os conhecimentos para uma melhor prestação de serviços.

- Gestão Ambiental - visa envolver todos os parceiros do TBC numa tentativa de adoção de uma abordagem holística e viável do desenvolvimento.

O PRPE identificou o Turismo Baseado na Comunidade - TBC como um dos setores nos quais as comunidades podem participar na cadeia produtiva de atividades comerciais e serviços relacionadas com o turismo.

O largo espectro de turismo responsável relativo às diversas alternativas (turismo ecológico, turismo étnico ou turismo comunitário, etc.), oferece ao Programa de Redução da Pobreza uma gama variada de oportunidades de ajuda às comunidades em países em vias de desenvolvimento. Os projetos baseados no TBC podem, assim, contribuir para um aumento das capacidades nacionais, fornecendo uma opção viável para o desenvolvimento comercial e para o espírito empresarial regionais.

O Programa de Redução da Pobreza pela Exportação - PRPE (Export-Led Poverty Reduction Programme EPRP), do International Trade Center - ITC (Centro de Comercio Internacional) é um programa que aspira o aumento da capacidade empreendedora de produtores e prestadores dos serviços nas comunidades (UNCTAD/ WTO, 2005). O objetivo final é melhorar a vida das comunidades tradicionais desfavorecidas e o aumento da qualidade e da quantidade da produção e dos serviços oferecidos pelas comunidades locais, ao passo que responde às necessidades dos principais mercados internacionais e nacionais.

Com base nestas premissas, as Entidades do CEPEC e da Associação dos Amigos de Iracambi tomaram a iniciativa de se associar Unidade de Conservação para desenvolver uma proposta de turismo responsável para o Território da Serra do Brigadeiro. De acordo com a realidade atual das iniciativas de turismo existente, mesmo ainda sem ser considerado como um destino de Turismo de Base Comunitária reconhecido pelo Ministério do Turismo, a proposta é planejar um gestão comprometida com este direcionamento.

A constatação de que as práticas turísticas em pequenas comunidades e o incremento das atividades turísticas apoiado por políticas públicas, não trouxeram os benefícios potenciais prometidos para as populações locais, leva alguns autores (BURSZTYN; BARTHOLO; DELAMARO, 2009) a questionar tais práticas e as políticas públicas que as sustentam como: a quem interessam? Quem são seus efetivos beneficiários? Não haveria um modelo alternativo? 
Com o intuito de responder a questionamentos como estes, o CEPEC, como organização não governamental, desenvolveu um modelo alternativo de turismo na cidade de Araponga/MG, situada na mesorregião Zona da Mata e microrregião de Viçosa (Figura 1), com uma área de $304,421 \mathrm{~km}^{2}$, uma população de 8.029 habitantes, contendo um grande potencial turístico, uma rica biodiversidade e uma beleza cênica exuberante. No município se encontra instalada a sede administrativa do Parque Estadual da Serra do Brigadeiro - PESB. O município ocupa 5.420 ha da área total da Unidade de Conservação, correspondendo a $41,3 \%$ em relação à UC e 17,85\% em relação ao município (PROMATA e IEF, 2007).

O PESB apresenta grande potencial ecoturístico nos quesitos de contemplação, fotografia, esportes radicais, turismo científico e educação ambiental, atividades previstas no Decreto Estadual № 217241981 de 23/11/1981, que regulamenta os Parques Estaduais instituindo como objetivo principal destas áreas: preservação, estudos, pesquisas, trabalhos de interesse científico e o oferecimento de condições para recreação, turismo e atividades educativas e de conscientização ecológica (BORGES, 2006, p.64)

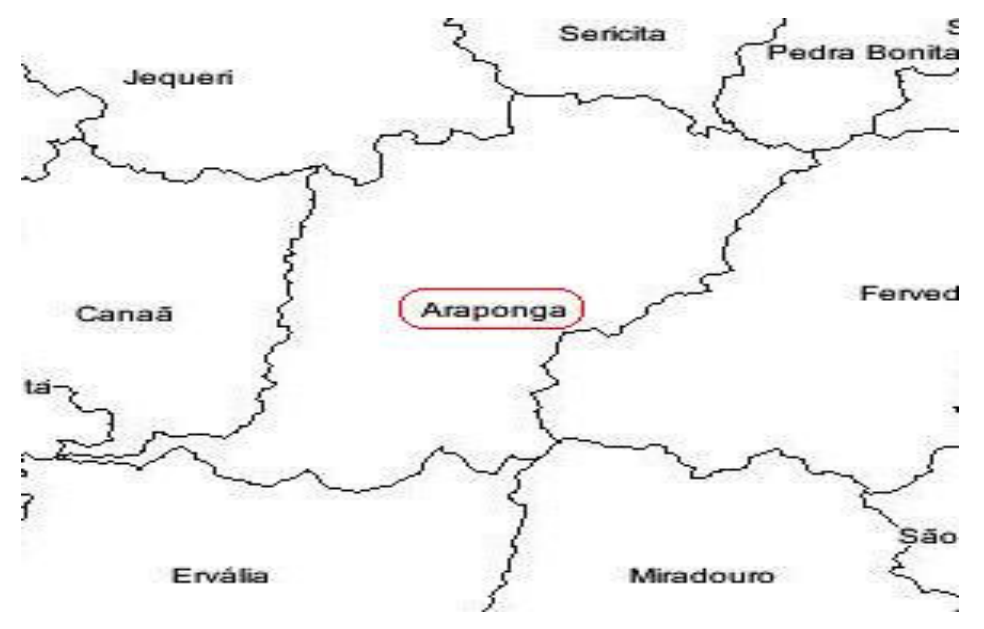

Figura 1 - Mapa do município de Araponga/MG e suas divisas.

Com este trabalho procurou-se levantar o interesse e as expectativas do turista em relação à região, de forma a se ter melhor conhecimento da realidade para permitir ações descentralizadas, com o intuito de gerar estratégias que permitam elaborar roteiros turísticos com maior envolvimento da população anfitriã nesta atividade. Desta forma, o projeto Boas Práticas de Turismo Comunitário, apoiado pelo Ministério do Turismo, será a mola propulsora de ações que buscará aproximar o consumidor final aos atrativos e produtos turísticos, com ações de gestão comunitária.

Segundo Maldonado (2009) o patrimônio comunitário é formado por um conjunto de valores e crenças, conhecimentos e práticas, técnicas e habilidades, instrumentos e artefatos, lugares e representações, terras e territórios, assim como todos os tipos de manifestações tangíveis e intangíveis existentes em um povo. Com base nes- 
Perfil dos turistas do Parque Estadual da Serra do Brigadeiro: subsídios para o turismo comunitário.

tas premissas, a região do entorno do Parque Estadual da Serra do Brigadeiro constituiu o território da Serra do Brigadeiro. Neste, expressam seu modo de vida e organização social, sua identidade cultural e suas relações com a natureza. Como consequência destes valores, o turismo abre vastas perspectivas para a valorização do acervo do patrimônio comunitário. Maldonado (2009) também afirma que diversas avaliações têm mostrado que, graças ao turismo, as comunidades estão cada vez mais conscientes do potencial de seus bens patrimoniais, ou seja, do conjunto de recursos humanos, culturais e naturais, incluindo formas inovadoras de gestão de seus territórios.

\section{Rede TRAF - Ferramenta de Gestão}

No Brasil, a Rede de Turismo Rural na Agricultura Familiar - REDE TRAF está presente em 24 estados com mais de 350 instituições atuantes que já participaram de alguma metodologia do Programa Nacional de Turismo Rural na Agricultura Familiar PNTRAF" ${ }^{2}$. O Turismo Rural na Agricultura Familiar é entendido como "a atividade turística que ocorre na unidade de produção dos agricultores familiares que mantêm as atividades econômicas típicas da agricultura familiar, dispostos a valorizar, respeitar e compartilhar seu modo de vida, o patrimônio cultural e natural, ofertando produtos e serviços de qualidade e proporcionando bem estar aos envolvidos" (BRASIL, 2004 p.08)

O que pretendem o Ministério do Desenvolvimento Agrário, o Ministério do Turismo e parceiros é trabalhar de forma integrada, utilizando-se de toda atividade turística no meio rural como fator de mobilização proporcionando retorno financeiro e meIhores condições de vida aos produtores e comunidades rurais (REDE TRAF, 2003).

O Turismo Rural na Agricultura Familiar vem ocorrendo em determinadas regiões e é produto das iniciativas promovidas pelos agricultores com apoio de entidades ligadas à Assistência Técnica e Extensão Rural e entidades da sociedade civil, em organizações comunitárias, formais e informais, gerando novas formas de trabalhos e negócios diversificados (BRASIL, 2004).

Segundo o Plano de Desenvolvimento Territorial do Território da Serra do Brigadeiro, foram definidos oito eixos temáticos. Este documento traz os debates realizados e a busca do desenvolvimento com sustentabilidade para a região (CTA-ZM, 2004). No eixo Turismo Rural, pretende-se explorar o potencial turístico do Parque Estadual da Serra do Brigadeiro de maneira a promover a qualidade de vida das comunidades sem, no entanto, descaracterizá-las e/ou desrespeitá-las. Os benefícios devem permitir e facilitar a circulação de recursos dentro do território com o intuito de gerar ocupações rentáveis aos moradores/as, visando o desenvolvimento econômico, social e ambiental.

Conforme o CTA-ZM (2004), as ações que estão sendo trabalhadas no Território, são: 
- Elaboração do Plano de Turismo Sustentável do Território;

- Capacitação de moradores/as para o turismo;

- Caracterização do perfil turístico da região;

- Busca de recursos para investir nas propriedades;

- Promoção e discussão do turismo adequado para cada município;

- Construção de Centros de Informações Turísticas;

- Incentivo a eventos culturais envolvimento das comunidades;

- Melhoria da infra-estrutura de estradas e sinalização das mesmas.

O conceito de economia solidária que se pretente instalar compreende uma diversidade de práticas econômicas e sociais organizadas sob a forma de cooperativas, associações, clubes de troca, empresas, redes de cooperação, entre outras, que realizam atividades de produção de bens, prestação de serviços, finanças solidárias, trocas, comércio justo e consumo solidário (MTE; SENAES, 2006). Esta ótica solidária na economia vem se apresentando como uma ferramenta para esta nova categoria de turismo, possibilitando organizar, de forma inovadora, fontes alternativas de geração de trabalho e renda.

Com esta contextualização, Irving (2009) nos diz que o turismo de base comunitária pode ser o "encontro" entre identidades, no sentido de compartilhamento e aprendizagem mútua. Neste caso, seu planejamento deve considerar "o compromisso ético, de respeito e engajamento de 'quem está' e de 'quem vem' e o intercâmbio real entre os sujeitos 'que recebem' e os que 'são recebidos' e, destes, com o ambiente no qual interagem. Sem essa interação, a troca de valores não se efetiva e o 'espaço da interação' ganha contornos apenas circunstanciais". Assim, além da expectativa do turista em relação ao local que visita existe a dos residentes do destino em relação à visita. Na maioria das vezes, o turismo de base comunitária transcende ás expectativas por haver uma cumplicidade entre visitantes e comunidade envolvida com a atividade turística, numa perspectiva de ganho mutuo.

\section{Turismo de Base Comunitária - Ferramenta de Comercialização}

O turismo de base comunitária é conceituado pelo Ministério do Turismo (2006), como um modelo de desenvolvimento turístico, orientado pelos princípios da economia solidária, associativismo, valorização da cultura local, e, principalmente, protagonizado pelas comunidades locais, visando à apropriação por parte dessas, dos benefícios advindos da atividade turística. As características ambientais da Serra do Brigadeiro aliado ao perfil sócio cultural do território nos indicam que o turismo de base comunitário com enfoque na agricultura familiar tem potencial para ser o direcionamento da atividade turística regional. 
Perfil dos turistas do Parque Estadual da Serra do Brigadeiro: subsídios para o turismo comunitário.

Segundo a Rede Turismo Comunitário ${ }^{3}$, as deficiências da oferta de turismo comunitário podem assim ser caracterizadas:

- Oferta dispersa e fragmentada, carente de estruturas e mecanismos regulares de cooperação interna para organizá-la e externa para potencializá-la. Apesar das vantagens das parcerias serem percebidas, os esforços empreendidos ainda são incipientes e pouco sistemáticos.

- Escassa diversificação dos produtos turísticos cujos componentes são baseados exclusivamente em fatores naturais e herdados. Existe potencial e vontade para empreender inovações que superem o mimetismo predominante.

- Gestão profissional limitada, tanto operacional como gerencial dos negócios; as tendências e o funcionamento da indústria do turismo são desconhecidos. As aspirações das comunidades de acesso a serviços de informação e capacitação permanecem amplamente insatisfatórias.

- Qualidade heterogênea dos serviços, com predominância de qualidade média e baixa. A competência aguda com outras empresas tende a resolver-se somente em curto prazo e através da baixa de preços.

- Posicionamento incerto e imagem pouco divulgada do turismo comunitário em mercados e segmentos dinâmicos: a promoção e comercialização são realizadas geralmente, por meios rudimentares, individuais e diretos.

- Deficiência dos mecanismos de informação, comunicação e organização comercial: a fraca representação e capacidade para negociação com outros agentes da cadeia turística não permite a tomada de decisões estratégicas, além do horizonte diário.

- Participação marginal ou subordinada de mulheres e suas associações na concepção e condução de projetos turísticos e, consequentemente, na captação de benefícios.

- Déficit notável de serviços públicos: rodovias, eletricidade, água potável, saneamento ambiental e esgoto, comunicações e sinalização turística. As comunidades não são capazes de cobrir estes custos; isto é responsabilidade dos governos locais ou nacionais.

A demanda turística explica, em uma de suas finalidades, o comportamento do consumidor, tendo em vista suas decisões de compra de bens e serviços que estão à disposição no mercado turístico (BROWN, 2005). Sob o enfoque econômico, o consumidor tem como objetivo primordial a obtenção da máxima satisfação de seus gastos, através da escolha da melhor combinação possível dos produtos turísticos. Sob outra ótica, a demanda também avalia a oferta destes produtos, no momento em que os consumidores não praticam, não exercem, não atuam, não vivenciam a vida no ambiente em que foram produzidos tais produtos. Nestes casos, não se está praticando o 
turismo de base comunitária, pois não se está interagindo com a produção dos bens e serviços nas regiões de visitação.

Para que esta interação seja alcançada da melhor forma possível, a Rede TURISOL - Turismo Solidário ${ }^{4}$ identifica os seguintes princípios que devem ser trabalhados:

1. A comunidade deve ser proprietária dos empreendimentos turísticos e gerenciar coletivamente a atividade.

2. A comunidade deve ser a principal beneficiária da atividade turística, para o desenvolvimento e fortalecimento da Associação Comunitária.

3. A principal atração turística é o modo de vida da comunidade, ou seja, sua forma de organização, os projetos sociais que faz parte, formas de mobilização comunitária, tradição cultural e atividades econômicas.

4. As atividades que fazem parte do cotidiano que o turista vai experimentar devem proporcionar intercâmbio cultural e aprendizagem ao visitante.

5. Os roteiros respeitam as normas de conservação da região e procuram gerar o menor impacto possível no meio ambiente.

6. Comunidades e visitantes participam da distribuição justa dos recursos financeiros.

7. Busca por envolvimento de diversos elos da cadeia do turismo no benefício das comunidades, por meio da parceria social com agências de turismo.

As demandas percebidas pelos ecoturistas têm sido, de acordo com SWARBROOKE (2000), a autenticidade da arquitetura, no setor de auto-acomodação, com a conversão de construções tradicionais em meios de hospedagem para turistas, como nas zonas rurais do sul da França. Esta constatação também pode ser observada no Brasil em diversas regiões, quando se enfatizam os traços culturais característicos Que podem ser de interesse do visitante.

O envolvimento das comunidades nas etapas da operacionalização e organização desta categoria de turismo permite encontrar as particularidades das regiões que permitem atrair turistas motivados a vivenciar esta troca de saberes. O pertencimento a certas tradições pode, assim, ser um atrativo relevante para os roteiros turísticos.

Segundo Maldonado (2009), existem empresas comunitárias como parte da economia social, que mobilizam recursos próprios e valorizam o patrimônio comum, com a finalidade de gerar ocupação e meios de vida para seus membros. Assim, a finalidade da empresa comunitária não é lucro nem a apropriação individual dos benefícios que são gerados, e sim a sua distribuição equitativa, através do investimento em projetos de caráter social ou podendo ser enriquecido ainda com produção de itens diversos. 
Perfil dos turistas do Parque Estadual da Serra do Brigadeiro: subsídios para o turismo comunitário.

Ainda sobre turismo de base comunitária, Silva, Ramiro e Teixeira (2009) propõem que seja utilizado, de forma sinérgica, as potencialidades do atrativo ambiental para a melhoria dos resultados econômicos e da qualidade de vida local. Com a valorização da cultura e a preservação do meio ambiente, pode-se evitar que o crescimento do turismo provoque uma concentração desordenada do capital produtivo e social, promovendo o acesso a bens e a serviços públicos. Alem disso, promove-se a integração com outros setores, e se trabalha a economia de base local.

\section{Material e Métodos}

Um questionário foi elaborado e aplicado aos turistas durante o feriado do carnaval de 2009_em três áreas distintas do Parque Estadual da Serra do Brigadeiro, a saber: na portaria oficial da Unidade de Conservação, na entrada para o Pico do Boné e na sede do município de Araponga. O numero de questionários respondidos por visitantes foi de 73 .

Uma entrevista também foi realizada no mesmo período de carnaval com os comerciantes da cidade de Araponga, em uma amostragem de 18 estabelecimentos.

Após a aplicação do questionário e das entrevistas, os resultados foram tabulados, e em seguida feita uma analise descritiva de todos os dados. Os resultados da pesquisa retornaram à comunidade no jornal informativo do CEPEC de circulação municipal.

\section{Resultados e Discussão}

Identificar o destino que se busca estabelecer para o turismo de base comunitária é uma questão prioritária para a aproximação com o mercado consumidor. Neste sentido, o território da Serra do Brigadeiro em seu atual estágio de percepção da atividade turística, identifica particularidades que o credencia a este tipo de turismo. Depende de um público que se identifique, através da interação com a comunidade anfitriã, podendo ser o elo que aproxima o consumidor e o destino sob uma nova ótica.

Em relação à hospedagem do turista no município, observa-se um grande interesse do visitante em acampar, representando $53 \%$ do total de pesquisados, o que comprova a preferência do turista por lugares que tenham possibilidades de se ter um contato maior com a natureza, como mostra a Figura 2. Além disso, as poucas opções de hospedagem não têm um sistema de divulgação como placas ou outros meios. Esta realidade deverá ser mudada com as ações do projeto de boas práticas, quando se buscará dotar a região de uma sinalização dos empreendimentos da agricultura familiar com a atividade de turismo. 
Moraes, W.V.; Ribeiro, G.A.; Dornelas, V.F.; Cardoso, R.M.; Araponga, I.F.

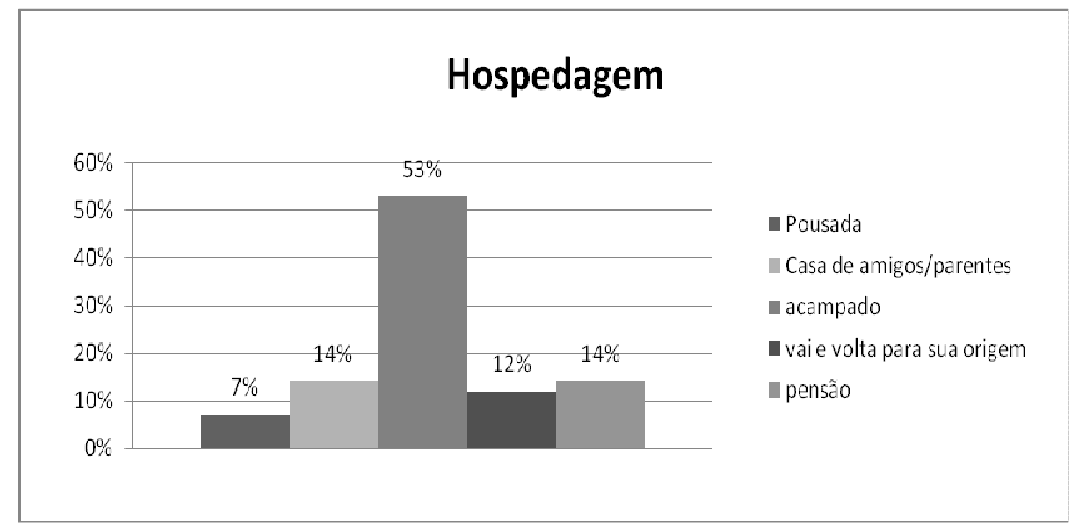

Figura 2 - Meios de hospedagem utilizados pelos turistas. Fevereiro/2009.

A pouca diferença com relação à idade dos turistas (Figura 3), pode facilitar a atividade dentre os que praticam a agricultura familiar, que têm o potencial de serem empreendedores dos meios de hospedagem. Uma vez que a maioria dos visitantes é de adultos de até 35 anos, que, em geral, estão à procura de novidades nas suas experiências de viagens. Estes visitantes adultos podem encontrar aventuras em locais ainda bastante intocados em termos ambientais e culturais, como é o território da Serra do Brigadeiro. Esta informação ajuda a direcionar a formatação dos roteiros que serão implantados nesta etapa. Esta informação para o poder público permite adequar o calendário de eventos e a programação voltada para estes jovens que, em sua maioria, são da Universidade Federal de Viçosa.

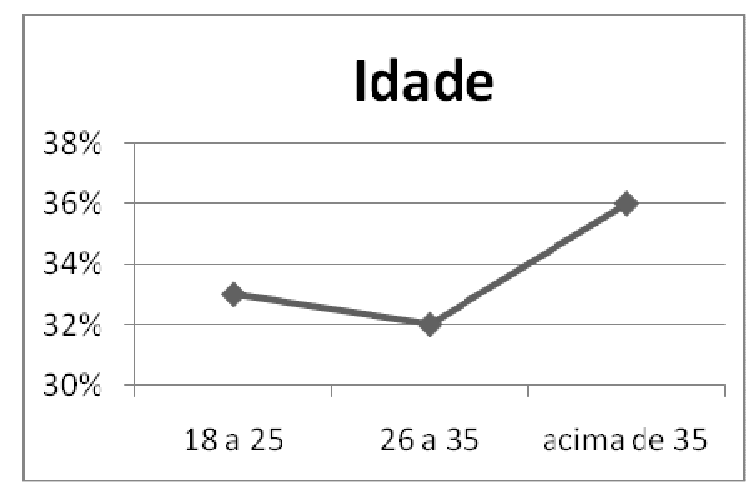

Figura 3 - Idade dos visitantes. Fevereiro/2009.

Dentre os atrativos turísticos que a cidade oferece, o Pico do Boné foi apontado por $16 \%$ como o lugar mais frequentado pelos turistas, seguido das Cachoeiras da Laje com $14 \%$ e a do Pio com $12 \%$. Percebe-se que uma quantidade considerável de visitantes (19\%) não responderam a esta questão (deixadas em branco), o que indica 
Perfil dos turistas do Parque Estadual da Serra do Brigadeiro: subsídios para o turismo comunitário.

haver uma carência de informação dos atrativos e de infra-estrutura turística da região. Na sede do PESB estão concentradas várias trilhas interpretativas e o centro de visitantes, locais de infra-estrutura específicas de uso público da Unidade de Conservação. No entanto, com base nas respostas dos entrevistados, apenas $6 \%$ visitaram estas áreas. O que surpreende é que o visitante que vai a cachoeira do Pio, de propriedade de uma família de agricultores, passa obrigatoriamente pela sede do PESB, o que reforça a necessidade de uma maior gestão com participação comunitária, como mostra a Figura 4.

A Fazenda do Brigadeiro, o Cruzeiro e a Igreja são atrativos que se encontram no interior do PESB. A Pousada Vitarelli e o Vale da Lua são empreendimentos particulares e não caracterizam a agricultura familiar, sendo o último onde se encontra um dos campings locais. O "seu" Dico, proprietário da Pousada Remanso é um agricultor familiar que também serve refeição e aluga quartos e tem o camping mais utilizado. Já a Cachoeira do Pio é de propriedade de um agricultor familiar, onde também se pode acampar, e conta com um pequeno bar e uma lanchonete.

Os dados apresentados na Figura 4 demonstram que os atrativos mais valorizados se encontram nas propriedades de particulares, sendo muitos que praticam a agricultura familiar, a grande maioria, precisam ser valorizados para deter de fato os benefícios da atividade. Portanto, a gestão da atividade precisa ser melhor trabalhada através de roteiros e capacitações diversas para que se possa implantar o Projeto Boas Práticas.

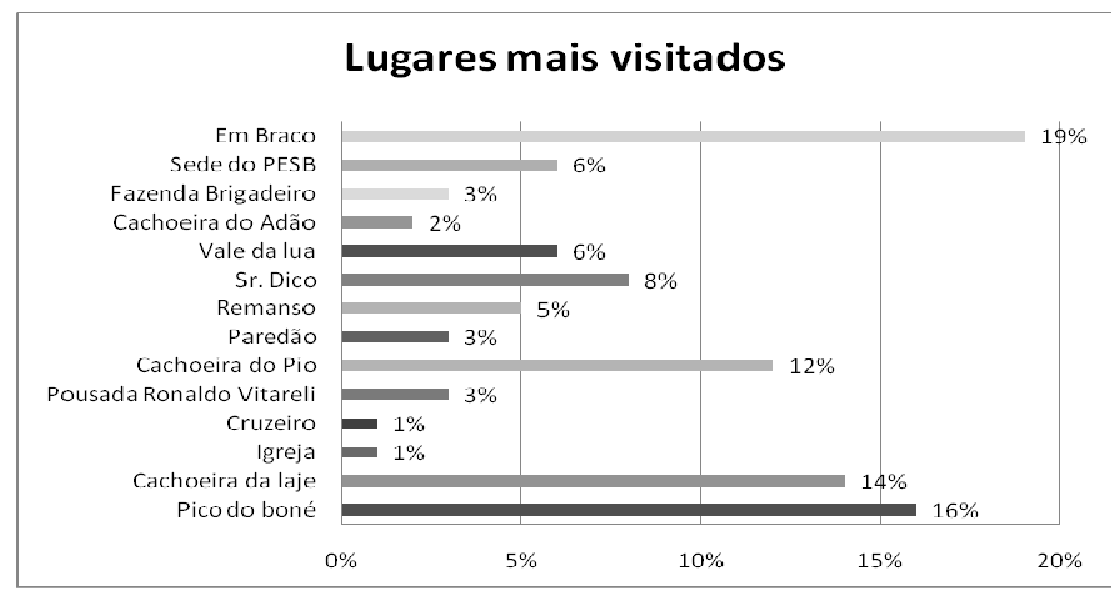

Figura 4 - Lugares mais visitados pelos turistas no entorno do PESB. Fevereiro/2009.

Quando questionados sobre a disposição em pagar por atividades, produtos e serviços como especificados na Figura 5 , foi constatado que $20 \%$ estão interessados em se hospedar na casa de agricultores familiares, maior interação e potencial de se ter uma experiência única e de se conhecer melhor a região. Uma pequena parcela, $3 \%$ dos entrevistados, tem vontade de conhecer a região com profissionais aptos, ou seja, guias conhecedores do município. 
Devido a faixa etária predominante, existe uma demanda por se praticar esportes radicais, observado em $32 \%$ das respostas. A cavalgada, uma atividade nova e que tem conquistado vários adeptos, foi mencionada por $9 \%$ dos entrevistados. Uma parcela considerável $(24 \%)$ procuram as propriedades rurais para conhecer e tornar o passeio mais dinâmico e agradável, pois possibilita um contato maior com o povo local, vivenciando a lida do campo como tratos de animais e agroecologia, entre outros. $\mathrm{O}$ artesanato constou em $12 \%$ das entrevistas, pois há um desejo de consumir algo feito regionalmente. Este dado pode nortear ações futuras, pois a região não apresenta muitos produtos, e esta á uma prática com potencial de agregar valores à economia das famílias rurais. A realização de um catálogo dos produtos e serviços do turismo de base comunitária será um dos resultados desta fase do Projeto Boas Práticas, de modo a facilitar a comercialização dos já existentes e fomentar sua diversificação.

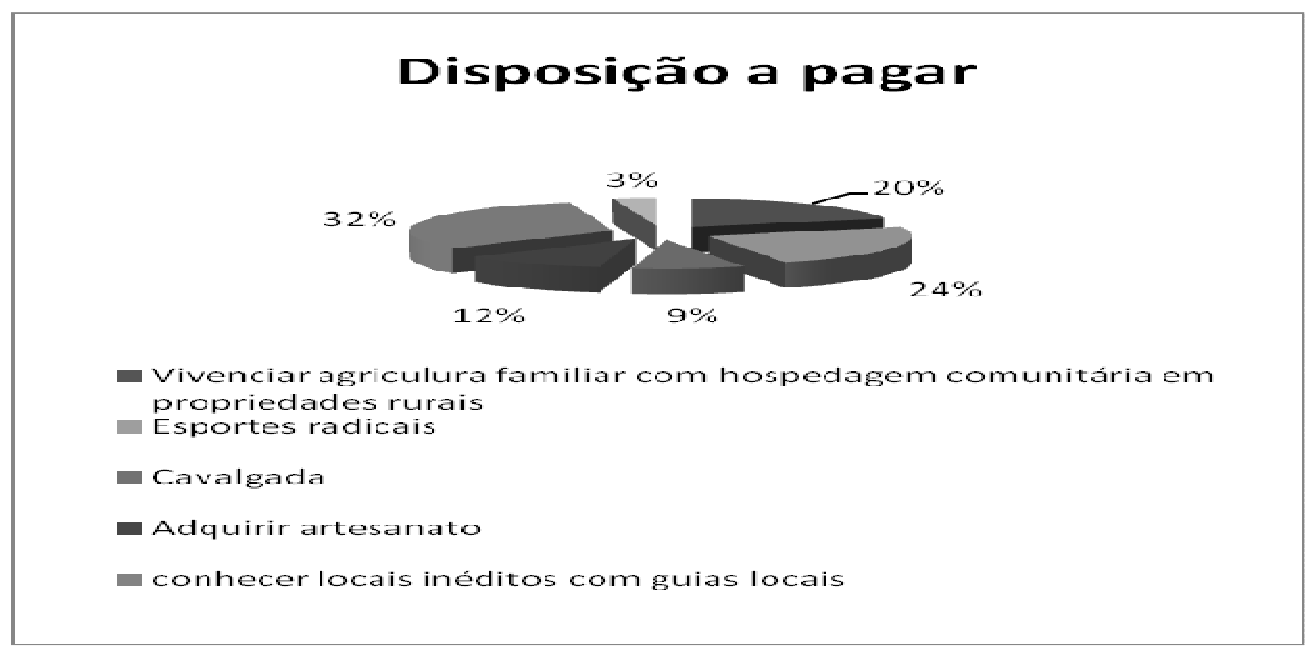

Figura 5 - Atividades em que o turista tem disposição a pagar. Fevereiro/2009.

$\mathrm{Na}$ Tabela 1, foram avaliadas as infra-estruturas básicas e turísticas da região do entorno do PESB. $O$ atendimento e a alimentação são os pontos mais mencionados, o que poderá trazer ganhos para a cidade de Araponga. Com relação ao acesso à região e aos atrativos foi detectado que este se encontra em péssimas condições, sendo esta responsabilidade dos gestores do turismo no município e dos governos locais, o que pode ser resultado de desarticulação dos tomadores de decisão.

Percebe-se que os preços das visitas estão sendo trabalhado de forma coerente, sem abusos e contradições, segundo as respostas obtidas. O lixo ainda não é preocupante, mas se não houver o cuidado de se trabalhar esta questão, por parte dos gestores do turismo, poderá se tornar um problema e atrapalhar a qualidade dos atrativos e consequentemente da região. 
Perfil dos turistas do Parque Estadual da Serra do Brigadeiro: subsídios para o turismo comunitário.

Tabela 1 - Conceitos que descrevem as opiniões dos turistas do PESB. Fevereiro/2009.

\begin{tabular}{|c|c|c|c|c|c|c|}
\hline Infra-estruturas & Ótimo & Bom & Regular & Ruim & Péssimo & Em Branco \\
\hline Acesso a região & $5 \%$ & $18 \%$ & $34 \%$ & $25 \%$ & $14 \%$ & $4 \%$ \\
\hline Acesso aos atrativos & $5 \%$ & $41 \%$ & $25 \%$ & $16 \%$ & $4 \%$ & $8 \%$ \\
\hline Infra-estrutura da cidade & $12 \%$ & $36 \%$ & $25 \%$ & $7 \%$ & $4 \%$ & $16 \%$ \\
\hline Infra-estrutura dos atrativos & $12 \%$ & $42 \%$ & $23 \%$ & $10 \%$ & $0 \%$ & $12 \%$ \\
\hline Hospedagem & $21 \%$ & $36 \%$ & $10 \%$ & $5 \%$ & $1 \%$ & $27 \%$ \\
\hline Alimentação & $25 \%$ & $40 \%$ & $10 \%$ & $3 \%$ & $0 \%$ & $23 \%$ \\
\hline Patrimônio histórico & $15 \%$ & $26 \%$ & $11 \%$ & $0 \%$ & $1 \%$ & $47 \%$ \\
\hline Informações recebidas & $18 \%$ & $45 \%$ & $16 \%$ & $5 \%$ & $1 \%$ & $14 \%$ \\
\hline Atendimento recebido & $29 \%$ & $48 \%$ & $8 \%$ & $3 \%$ & $0 \%$ & $12 \%$ \\
\hline Preço & $11 \%$ & $45 \%$ & $19 \%$ & $3 \%$ & $0 \%$ & $22 \%$ \\
\hline Opção de o que fazer & $19 \%$ & $36 \%$ & $23 \%$ & $7 \%$ & $3 \%$ & $12 \%$ \\
\hline Condição do lixo & $16 \%$ & $36 \%$ & $27 \%$ & $5 \%$ & $5 \%$ & $10 \%$ \\
\hline Sinalização & $12 \%$ & $27 \%$ & $21 \%$ & $21 \%$ & $11 \%$ & $8 \%$ \\
\hline
\end{tabular}

Os resultados da Tabela 1 apresentam médias, conforme a Figura 6 . O conceito bom obteve a melhor das médias, com $37 \%$, e o péssimo foi o que apresentou o menor índice, com apenas 3\%. As respostas em branco tiveram um resultado bem significante $(17 \%)$, o que pode ser justificado pelo desconhecimento dos visitantes em relação aos patrimônios históricos e, também, pelo fato da maioria dos visitantes estarem acampados e optarem por prepararem sua própria alimentação.

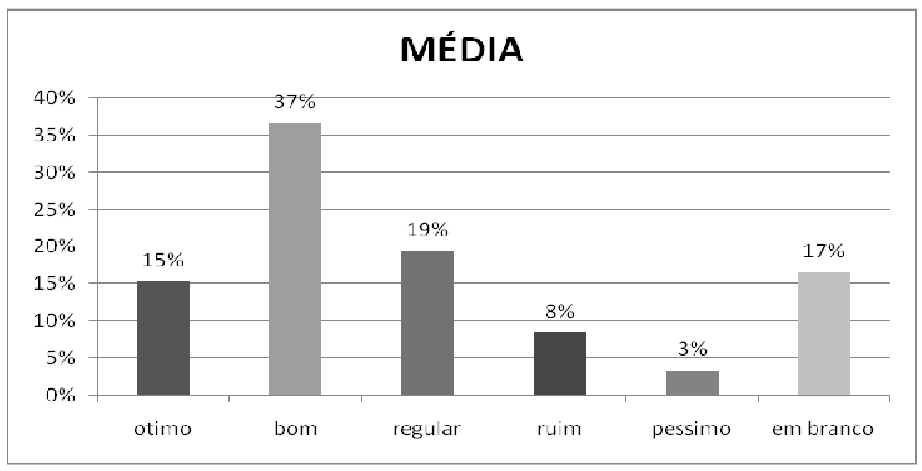

Figura 6 - Média dos conceitos que melhor descreve o entorno do PESB. Fevereiro/2009.

As entrevistas realizadas com os comerciantes da sede do município de Araponga permitiram reconhecer as categorias de negócios, como o perfil básico estrutural da capacidade empreendedora dos comerciantes face à atividade de turismo.

É válido destacar que a cidade de Araponga não apresenta tradição no carnaval. Assim, os turistas que se encontram na sede do município, em sua maioria, são parentes, convidados e amigos da população residente. O fluxo turístico que a cidade recebe se distribui pela zona rural onde se hospeda. A minoria restante retorna para a 
Moraes, W.V.; Ribeiro, G.A.; Dornelas, V.F.; Cardoso, R.M.; Araponga, I.F.

sua cidade de origem, talvez por não haver tanta oferta de pousadas e alojamentos.

Foram entrevistados todos os estabelecimentos comerciais da praça central, onde o carnaval aconteceu. Com relação aos tipos de negócios existentes, percebese insuficiência de empreendimentos de hospedagem e alimentação no município. Apesar da existência do PESB já ter mais de 10 anos, ainda não despertou na sede do município esta possibilidade de negócio (Tabela 2). Um dos motivos pode ser a falta de um calendário de eventos que estimule um fluxo de visitação. A cidade é desprovida de um supermercado com itens relevantes para uma sociedade turística. Sendo assim, o turista chega ao município com os itens de consumo já adquiridos em outras praças. Este fato inibe o mercado, pois por um lado o consumidor não busca os estabelecimentos existentes e, por outro, o fornecedor que adquire produtos capazes de atender as demandas do público visitante.

Tabela 2 - Caracterização dos negócios na cidade de Araponga / MG. Fevereiro/2009.

\begin{tabular}{|c|c|c|}
\hline TIPO DE NEGócIO & QUANTIDADE & $\%$ \\
\hline Mercearia & 2 & 12 \\
\hline Loja de roupas & 2 & 12 \\
\hline Padaria & 2 & 12 \\
\hline Restaurante & 1 & 05 \\
\hline Pensão & 1 & 05 \\
\hline Bar & 4 & 22 \\
\hline Lan house & 1 & 05 \\
\hline Mercado & 2 & 12 \\
\hline Posto de gasolina & 1 & 05 \\
\hline Agricultor que recebe turista & 1 & 05 \\
\hline Pousada & 1 & 05 \\
\hline TOTAL & 18 & 100 \\
\hline
\end{tabular}

Considerando que ninguém espera ter prejuízo em o seu negócio, podemos concluir pela Tabela 3 que, 66\% (44+22) dos comerciantes tiveram lucro e 34\% não se planejaram para um período de alta visitação, e por isso não obtiveram o lucro esperado. A falta de planejamento pode ser justificado pela falta de conhecimento das necessidades do consumidor.

Tabela 3 - Caracterização dos negócios na cidade Araponga / MG. Fevereiro/2009.

\begin{tabular}{|l|c|c|}
\hline \multicolumn{1}{|c|}{ Seu negócio no carnaval foi } & Quantidade & $\%$ \\
\hline acima do esperado & 4 & 22 \\
\hline abaixo do esperado & 6 & 34 \\
\hline igual ao esperado & 8 & 44 \\
\hline Total & 18 & 100 \\
\hline
\end{tabular}

$\mathrm{Na}$ caracterização do perfil do empreendedor, percebe-se pela Tabela 4 que $67,5 \%(62+5,5)$ conseguiram satisfazer as necessidades dos clientes, o que pode ser melhorada. Estes dados reafirmam algumas informações já comentadas que são 
Perfil dos turistas do Parque Estadual da Serra do Brigadeiro: subsídios para o turismo comunitário.

a falta de calendário de eventos para estimular o fluxo de turistas na sede do município, o desconhecimento do perfil do consumidor turista, o pouco entendimento da atividade turística, a capacidade limitada de gerenciamento, entre outras que caracterizam o perfil do empreendedor de uma pequena cidade interiorana do estado de Minas Gerais.

Tabela 4 - Caracterização dos negócios na cidade de Araponga / MG. Fevereiro/2009.

\begin{tabular}{|l|c|c|}
\hline \multicolumn{1}{|c|}{ Você conseguiu atender aos pedidos dos clientes? } & Quantidade & $\%$ \\
\hline todos os pedidos & 11 & 62 \\
\hline menos da metade dos pedidos & 1 & 5,5 \\
\hline não atendi porquê não tinha a mercadoria pedida & 2 & 11 \\
\hline a metade dos pedidos & 3 & 17 \\
\hline não atendi mais porquê faltou mercadoria & 0 & 0 \\
\hline atendeu mais da metade dos pedidos & 1 & 5.5 \\
\hline Total & 18 & 100 \\
\hline
\end{tabular}

Conforme a Tabela 5 , percebe-se que a atividade turística é muito nova na cidade, pois os resultados mostram que os comerciantes estão despreparados para trabalhá-la. Conforme mostra a pesquisa, $51 \%$ pretendem aumentar os estoques, 0 que os favorecerá se tiverem mais mercadorias/produtos. Estabelecer mecanismos de orientação gerencial para esta classe é pode aumentar o fluxo de receitas no município, pois o aumento de consumo poderá ser praticado também pelos moradores da cidade.

Tabela 5 - Caracterização dos negócios na cidade de Araponga / MG. Fevereiro/2009.

\begin{tabular}{|l|c|c|}
\hline \multicolumn{1}{|c|}{ O que pretende fazer para melhorar o seu negócio? } & Quantidade & $\%$ \\
\hline investir mais tempo com trabalho para o turismo & 2 & 10 \\
\hline aumentar meu estoque & 9 & 51 \\
\hline aumentar minhas opções de negócio. & 5 & 28 \\
\hline melhorar em tudo & 1 & 5,5 \\
\hline divulgar o negocio & 1 & 5,5 \\
\hline Total & 18 & 100 \\
\hline
\end{tabular}

Existe a necessidade de se buscar maior harmonização da demanda e da oferta. Neste momento os bens e os serviços necessitados pelos turistas têm de ser adquiridos fora da comunidade local pelos empreendedores, o que ocorre quando a comunidade local não é capaz de fornecer um produto ou serviço pedido ou é incapaz de fornecê-lo em termos competitivos. Saber quais são os produtos e os serviços externos das comunidades locais pode resultar na identificação de oportunidades para estas comunidades e, ao mesmo tempo, fortalecer a união dos atores lideres do processo. Neste sentido, existe a necessidade de um constante monitoramento dos serviços com o intuito de aproximá-los da demanda e assim satisfazê-la.

Uma das melhores maneiras de aumentar os benefícios provenientes do turismo é reverter para a economia local a demanda dos turistas, ou seja, aproximar o consumidor de serviços do turismo com os empreendimentos de hospedagem, ali- 
mentação, operadores e empresas de transportes entre outros, com a comunidade anfitriã. Esta relação desperta nas comunidades anfitriãs as possibilidades de comércio através da atividade turística, possibilitando benefícios econômicos locais e, consequentemente, a redução de bens e serviços fornecidos por agentes externos à comunidade.

\section{Conclusão}

O PESB é hoje, para a região da Zona da Mata de Minas Gerais, uma área indispensável para o desenvolvimento sustentável, onde se deve considerar a inclusão social como sue mola propulsora. Assim, a atividade turística que vem se buscando para a região deve ocupar um papel de destaque, pois sua função como geradora de renda tem um potencial de ser benéfico a todos, se bem gerenciado.

No entanto, o que esta pesquisa demonstrou é que a cidade de Araponga, apresenta características relevantes, como:

- A mais próxima da referida Unidade de Conservação com condições reais de aumento de fluxo turístico devido à presença da portaria do PESB;

- A maior área no interior do PESB, o que implica em uma somatória de recursos financeiros advindos do ICMS Ecológico, disponível para investimentos na área do turismo ambiental;

- A que recebe maiores investimentos do órgão público estadual responsável pela administração do PESB, o Instituto Estadual de Florestas;

- A existência de empreendedores de base local, caracterizados pela agricultura familiar com produtos associados ao turismo;

- A presença de empreendedores predispostos a investir no setor de turismo;

- A interação da cidade com trabalhos diversos da Universidade Federal de Viçosa e de ONG's externas ao município, que a divulgam como modelo de conservação ambiental para o Brasil, estimulando um fluxo de turistas constantes.

O conhecimento dos impactos positivos ambientais, sociais e financeiros que a atividade turística pode proporcionar, deve ser conduzido de forma adequada. Neste sentido, iniciativas de ordenamento do turismo de base local precisam ser discutidas em toda a esfera da sociedade buscando apresentar os benefícios da atividade com propostas de gestão dentre as comunidades envolvidas com o processo turístico local. Por outro lado, a região caracterizada pela cidade de Araponga também reflete alguns pontos negativos que podem ser comuns a outras regiões do Brasil, como:

- Descomprometimento da gestão de empreendimentos de base local, devido a inexistência de um planejamento para uma política pública de turismo; 
Perfil dos turistas do Parque Estadual da Serra do Brigadeiro: subsídios para o turismo comunitário.

- Pouca diversidade de produtos turísticos sendo disponibilizados ao consumidor, devido a limitada capacidade gerencial dos empreendedores de turismo de base local;

- Infraestrutura básica e turística deficiente nos sítios turísticos, por causa da má utilização dos recursos financeiros sem definição de prioridades de investimento.

Como consequência, parece haver uma visão destorcida e limitada sobre a atividade turística de base local em todo o mercado. Os impactos negativos são percebidos não só pela comunidade local, que deixa de maximizar sua participação no fortalecimento deste turismo, como pelos visitantes, que acabam experimentando uma viagem aquém das suas expectativas e necessidades, e acabam não vivenciando os valores culturais, os produtos rurais e ambientais de uma região peculiar pautada na agricultura familiar.

No entanto, a força do turismo de base comunitária, mesmo com um planejamento incipiente e infra-estrutura inadequada para atender a esse fluxo turístico crescente, tem despertado uma nova forma de renda para o povo local com a concretização de vários meios de hospedagem domiciliar geridas pelas famílias agricultoras, prática que vem sendo denominado de hospedagem de montanha. Torna-se necessário, assim, a integração de entidades públicas e privadas na área de turismo, de modo a que apóiem a iniciativa. É importante promover este tipo de turismo que visa melhorias sociais e proteção ambiental antes que empresários sem esta visão venham a realizar atividades que apenas visem o lucro, não só no território da Serra do Brigadeiro como em outros destinos que ainda têm riquezas socioambientais a serem compartiIhadas com visitantes e residentes locais.

Sendo assim, o projeto de turismo de base comunitária, que está sendo implantado deve se preocupar em atender parâmetros sustentáveis de uso do entorno do PESB, assim como formatar roteiros de acordo com os princípios da REDE TRAF e da REDE TURISOL - Turismo Solidário permitindo a agregação de valor e renda á agricultura familiar. O projeto boas práticas deve, portanto, buscar estabelecer canais de visibilidade do que é um turismo responsável, justo e sustentável, de modo a inspirar outros a desenvolverem atividades que podem beneficiar a natureza e a coletividade.

\section{Referências Bibliográficas}

BURSZTYN, I.; BARTHOLO, R.; DELAMARO, M.. Turismo para quem? Sobre caminhos de desenvolvimento e alternativas para o turismo no Brasil. In: BARTHOLO, R.; SANSOLO, D.G.; BURSZTYN, I. Turismo de Base Comunitária diversidade de olhares e experiências brasileiras. Rio de Janeiro: Editora Letra e imagem, 2009, parte I, p.76 - 91.

BORGES, J. Relatório do diagnóstico de Uso Público do PESB. Rio de Janeiro: IEF. 2006. 77p.

BROWN, L. Competitive Marketing Strategy. $2^{a}$ edição. South Melbourne: Thomas Nelson. 2005. 135p. 
Moraes, W.V.; Ribeiro, G.A.; Dornelas, V.F.; Cardoso, R.M.; Araponga, I.F.

BRASIL. Ministério do Turismo. Diretrizes para o Desenvolvimento do Turismo Rural no Brasil. Brasília, MTur, 2004. 56p.

CTA-ZM. Plano Territorial de Desenvolvimento Sustentável - PTDRS Serra do Brigadeiro. Brasília: MDA. 2005. 81p.

INSTITUTO ESTADUAL DE FLORESTAS. Parque Estadual da Serra do Brigadeiro Plano de Manejo / Etapa I. 2002 (versão incompleta).

IRVING, M.A.. Reinventando a reflexão sobre turismo de base comunitária - inovar é possível? In: BARTHOLO, R.; SANSOLO, D.G.; BURSZTYN, I. Turismo de Base Comunitária diversidade de olhares e experiências brasileiras. Rio de Janeiro: Editora Letra e imagem, 2009, parte I, p.108 - 121.

JAIN, N. LAMA, W. Community-based Tourism For Conservation And Development: A Resource Kit. Washington: The Mountain Institute. 125p. 2000.

MALDONADO, C. O turismo rural comunitário na América Latina: gênesis, características e políticas. In: BARTHOLO, R.; SANSOLO, D.G.; BURSZTYN, I. Turismo de Base Comunitária diversidade de olhares e experiências brasileiras. Rio de Janeiro: Editora Letra e imagem, 2009, parte I, p.25 - 44.

MINISTÉRIO DO DESENVOLVIMENTO AGRÁRIO. Referências para o Desenvolvimento Territorial Sustentável. Série Textos para Discussão. No. 04. Brasília: MDA 2003. $35 \mathrm{p}$.

MINISTÉRIO DO DESENVOLVIMENTO AGRÁRIO. Programa de Desenvolvimento Territorial Sustentável: Território da Serra do Brigadeiro. Brasília: MDA/SDT. 2003. 35p. (mimeo).

MINISTÉRIO DO TRABALHO E EMPREGO. Secretaria Nacional de Economia Solidária SENAES. Atlas da Economia Solidária no Brasil. Brasília: MTE 2006. 61p.

MCKERCHER, B.. Turismo de Natureza - Planejamento e Sustentabilidade. São Paulo: Contexto. 2002. 303p.

PROMATA; IEF. Plano de Manejo da Serra do Brigadeiro - Resumo Executivo. Belo Horizonte. Outubro, 2007. $15 \mathrm{p}$.

REDE TRAF. Diretrizes para o Desenvolvimento do Turismo Rural na Agricultura Familiar. Belo Horizonte: Rede TRAF, MDA - Ministério do Desenvolvimento Agrário. 2003. 23p.

SILVA, T.P.K.; RAMIRO, R.C.; TEIXEIRA, B.S. Fomento ao Turismo de Base Comunitária: a experiência do Ministério do Turismo. In: BARTHOLO, R.; SANSOLO, D.G.; BURSZTYN, I. Turismo de Base Comunitária diversidade de olhares e experiências brasileiras. Rio de Janeiro: Editora Letra e imagem, 2009, parte I, p.361-368.

SWARBROOKE, J. Turismo sustentável: turismo cultural, ecoturismo e ética. Volume 5. São Paulo: Ed. Aleph, 2000. 135p.

UNCTAD/WTO. Módulo de Treinamento para o Sucesso do Turismo Baseado na Comunidade - TBC no Âmbito do PRPE - Programa de Redução da pobreza através da Exportação. Internacional Trade Center - ITC. 96p. 2005. 
Perfil dos turistas do Parque Estadual da Serra do Brigadeiro: subsídios para o turismo comunitário.

\section{NOTAS:}

${ }^{1} \mathrm{O}$ presente trabalho teve a colaboração dos estagiários Renato e Ivanete do CEPEC e do técnico da Associação Amigos de Iracambi. O mesmo trabalho se insere no projeto Boas Práticas de Turismo Comunitário da Serra do Brigadeiro com apoio financeiro do Ministério do Turismo, sendo objeto de tese de doutorado do Departamento de Engenharia Florestal da Universidade federal de Viçosa.

2 PNTRAF - Programa Nacional de Turismo Rural na Agricultura Familiar http:// www.mda.gov.br/saf/arquivos/0708519756.pdf , acessado em maio de 2009.

3 Rede de Turismo Comunitário - http://www.redturs.org/nuevaes/articulo.php , acessado em maio de 2009.

${ }^{4}$ Rede TURISOL - Turismo Solidário - http://turisol.wordpress.com/conceitos/ , acessado em maio de 2009.

Werter Valentim Moraes: Universidade Federal de Viçosa.

Email: wvmoraes@hotmail.com

Link para o currículo Lattes: http://lattes.cnpq.br/9223383660522009

Guido Assunção Ribeiro: Universidade Federal de Viçosa.

Email: gribeiro@ufv.br

Link para o currículo Lattes: http://lattes.cnpq.br/9849187635825179

Virgilio Furtado Dornelas: Associação Amigos de Iracambi.

Email: turismo@iracambi.com

Renato Miranda Cardoso: CEPEC - Centro de Pesquisa e Promoção Cultural. Email: mirecardoso@yahoo.com.br

Ivanete Freitas Araponga: Centro de Pesquisa e Promoção Cultural.

Email: ivanete@hotmail.com

Data de submissão: 19 de novembro 2009.

Data do aceite: 23 de maio de 2010. 